\title{
Die hormonelle Regulation der Magnesium-Verteilung
}

\author{
Von Th. GüNTher und Ch. Alter \\ Aus dem Pbysiologisch-Chemischen Institut der Freien Universität Berlin (Direktor: Prof. Dr. Dr. E. Schïtte)
}

(Eingegangen am 23. Mai 1966)

An männlichen Ratten untersuchten wir den Einfluß von Hypophysektomie, STH, Adrenalektomie, Aldosteron, Cortison, Methylthiouracil, Thyroxin, Parathyreoidektomie, Kastration, Testosteron, Ostradiol und Progesteron auf die Verteilung des Mg in Muskel und Leber.

Nach Hypophysektomie ist der Mg-Gehalt nur im Muskel reduziert. Unter STH nimmt das $\mathrm{Mg}$ in Serum und Muskel zu, in der Leber ab. - Nach Adrenalektomie steigt der Mg-Gehalt in Serum, Leber und Muskel. Substitution mit Aldosteron verhindert das Ansteigen des $\mathrm{Mg}$ im Serum vollständig, in der Leber teilweise und im Muskel überhaupt nicht. Cortison hat keinen Einfluß auf die Mg-Konzentration im Serum. Im Muskel wurde der Mg-Gehalt normalisiert und in der Leber noch unter den Wert der Kontrolltiere gesenkt.

Nach Verfütterung von Methylthiouracil war der Mg-Gehalt in Serum, Leber und Muskel abgesunken, nach Injektion von Thyroxin angestiegen. - Entfernen der Epithelkörperchen senkte den Mg-Gehalt in Serum und Leber. - Von den getesteten Sexualhormonen erhöhten Testosteron und Progesteron die Serum-Mg-Konzentration, Testosteron und Ostradiol den Mg-Gehalt im Muskel. Der Mg-Gehalt der Leber wurde durch Testosteron nicht beeinflußt und durch Ostradiol und Progesteron gesenkt.

Die Mechanismen, die die Mg-Verteilung ändern können, und die Wirkung eines veränderten $\mathrm{Mg}$-Gehaltes der Zellen auf ihren Stoffwechsel werden diskutiert.

The influence of hypophysectomy, STH, adrenalectomy, aldosterone, cortisone, methylthiouracil, thyroxin, parathyroidectomy, castration, testosterone, oestradiol and progesterone on the distribution of $\mathrm{Mg}$ in muscle and liver was studied in the male rat.

After hypophysectomy, the $\mathrm{Mg}$ level was decreased only in muscle. With $\mathrm{STH}$, the $\mathrm{Mg}$-level was increased in serum and muscle, but decreased in liver. - After adrenalectomy, the $\mathrm{Mg}$-level in serum, liver and muscle was increased. The increase of $\mathrm{Mg}$ was inhibited completely in serum, partly in liver and not at all in muscle by the administration of aldosterone. Cortisone had no influence on the $\mathrm{Mg}$ concentration in serum; the muscle- $\mathrm{Mg}$ was normalised, and the liver- $\mathrm{Mg}$ was depressed below that of control animals. - The $\mathrm{Mg}$-level of serum, liver and muscle was decreased after feeding methylthiouracil, and increased after the injection of thyroxin. - Parathyreoidectomy decreased the level of $\mathrm{Mg}$ in the serum and liver. - Of the tested sex hormones, testosterone and progesterone increased the concentration of serum- $\mathrm{Mg}$; testosterone and oestradiol increased the $\mathrm{Mg}$ level in muscle. Liver- $\mathrm{Mg}$ was not influenced by testosterone, but it was decreased by oestradiol and progesterone.

Mechanisms for the alteration of the $\mathrm{Mg}$-distribution, and the effect of a changed $\mathrm{Mg}$-content on cell metabolism are discussed.

Wir haben in früheren Mitteilungen die Einflüsse von Hormonen auf die $\mathrm{Na}-, \mathrm{K}=\mathrm{Cl}$ - und $\mathrm{H}_{2} \mathrm{O}$-Verteilung in Leber und Muskel untersucht und gezeigt, daß Hormone die im allgemeinen auf bestimmte Gewebe bzw. Organe einwirken, auch andere Körperzellen beeinflussen (1,2, 3). In der vorliegenden Arbeit wurden diese Untersuchungen auf das Verhalten des Magnesiums ausgedehnt.

$\mathrm{Mg}$ ist nach $\mathrm{K}$ das häufigste intrazelluläre Kation. Es ist unentbehrlicher Aktivator für zahlreiche Enzyme. Bisher sind mehr als $100 \mathrm{Mg}$-abhängige Enzyme bekannt. $\mathrm{Mg}$ liegt in der Zelle größtenteils als Komplex vor, nur $10-20 \%$ des Gesamt-Mg sind ionisiert. Die intrazelluläre $\mathrm{Mg}^{2+}$-Konzentration hat mit $1,5-3 \mathrm{mMol}$ ein Niveau, bei dem die meisten $\mathrm{Mg}$-abhängigen Enzyme halbmaximal bis maximal aktiviert sind (4). Änderungen im Gesamt-Mg-Bestand der Zelle könnten daher die intrazelluläre $\mathrm{Mg}^{2+}$-Konzentration beeinflussen und somit den Ablauf von Stoffwechselreaktionen verändern. Die vorliegende Arbeit berichtet deshalb über Änderungen des zellulären $\mathrm{Mg}$-Bestandes unter verschiedenen hormonellen Bedingungen.

\section{Methodik}

Für die Versuche verwendeten wir etwa gleich alte männliche Albinoratten, die Standardpreßfutter und Leitungswasser erhielten.

Aufarbeitung der Tiere und Bestimmungsmethoden Die Ratten wurden durch Genickschlag getötet. Sofort danach wurde aus dem noch schlagenden Herzen mit Kapillaren Blut für die Bestimmungen im Serum entnommen. Die Kapillaren wurden abgeschmolzen und zur Serumgewinnung zentrifugiert. Leber und identische Muskelstücke wurden herauspräpariert, von Blut und Bindegewebe befreit, in flüssiger Luft eingefroren und im VakuumExsikkator über Silikagel gefriergetrocknet.
Bestimmung des Wassergehaltes

Aus der Gewichtsdifferenz vor und nach Gefriertrocknung.

Bestimmung des Proteingebaltes im Serum

In $0,1 \mathrm{~m} l$ Serum wurde der Eiweißgehalt mit Biuretreagenz nach Weichselbaum bestimmt (5).

Bestimmung der Magnesium-Konzentration im Serum

Je $0,2 \mathrm{ml}$ Serum wurden mit $0,2 \mathrm{ml}$ aqua bidest. verdünnt (geeichte Blutzuckerpipette) und mit $2 \mathrm{ml} 10$-proz. Trichloressigsäure (,TCE“) enteiweißt. In $2 \mathrm{ml}$ des TCE-Extraktes wurde $\mathrm{Mg}$ nach Orange und Rhein (6) bestimmt.

\section{Bestimmung des Magnesiums in gefriergetrockneten Organen}

Etwa $10 \mathrm{mg}$ Trockensubstanz wurden mit $5 \mathrm{ml} 10$-proz. TCE $24 \mathrm{Stdn}$. im Eisschrank unter mehrmaligem Umrühren in Zentrifugengläsern extrahiert. In $2 \mathrm{ml}$ TCE-Extrakt wurde $\mathrm{Mg}$ nach OrANGE und Rhein (6) bestimmt. Veraschung und TCE-Extraktion ergaben, wie Vorversuche zeigten, identische Werte.

\section{Bestimmung der EZF}

Die Größe der EZF der meisten Versuchsgruppen wurde in früheren Versuchen bestimmt, in denen die Tiere in gleicher Weise vorbehandelt wurden $(1,2,3)$. Die EZF der restlichen Versuchsgruppen wurde, wie früher beschrieben (2), ermittelt.

Berechnung der Versuchsergebnisse

Umrecbnung in Frischgewicht (FG)

$$
\mathrm{FG}=\frac{\mathrm{TG}\left(100-\mathrm{H}_{2} \mathrm{O}\right)}{100}[\mathrm{mMol} / \mathrm{kg}]
$$

FG = Mg-Gehalt bezogen auf Frischgewicht TG $=$ Mg-Gehalt bezogen auf Trockengewicht $\mathrm{H}_{2} \mathrm{O}=$ Wassergehalt in $\%$

Berechnung des extrazellulären $\mathrm{Mg}$

$[\mathrm{Mg}]_{\mathrm{EZF}}=[\mathrm{Mg}]_{\mathrm{ev}} \cdot 0,75 \cdot \mathrm{FZZF}+[\mathrm{Mg}]_{\mathrm{ser}} \cdot 0,25 \mathrm{EZF}$

EZF $=$ Größe der EZF in $1 / \mathrm{kg}$

$[\mathrm{Mg}]_{\mathrm{EZF}}=$ extrazelluläres $\mathrm{Mg}$

$[\mathrm{Mg}]_{\mathrm{ev}}=\mathrm{Mg}$-Konzentration im extravasalen Raum

$[\mathrm{Mg}]_{\text {ser. }}=\mathrm{Mg}-$ Konzentration im Serum

Es wird vorausgesetzt, daß das Verhältnis extravasal/intravasal $=3: 1$ ist und bei allen Versuchsserien gleich ist. 
Die Mg-Konzentration im extravasalen Raum wurde aus einem Diagramm von WILLIs und Mitarbeitern (7) unter Berücksichtigung des Eiweißgehaltes im Serum abgelesen. Dabei wird angenommen, daß das extravasale $\mathrm{Mg}$ ein Ultrafiltrat des intravasalen ist.

Eine Fehlerbetrachtung, bei der die Fehler der Magnesium-, der Protein- und EZF-Bestimmung sowie die Unsicherbeit über das Verhältnis des intra- und extravasalen Anteils der EZF sowie die Unkenntnis des genauen Proteingehaltes der extravasalen Flüssigkeit berücksichtigt wurden, ergibt einen Gesamtfehler des extrazellulären Magnesiums von $\pm 15 \%$. Dies ist bedeutungslos, wenn man bedenkt, daß der extrazelluläre Anteil des Magnesiums im Gewebe nur 1\% des Gesamtbestandes ausmacht.

Berecbunung des intrazellulären Magnesiums

Der intrazelluläre Anteil ergibt sich nach folgender Formel:

$$
[\mathrm{Mg}]_{\mathrm{IZF}}=\frac{[\mathrm{Mg}]_{\text {ges. }}-[\mathrm{Mg}]_{\text {EZF }}}{1-\mathrm{EZF}}
$$

$[M g]_{\text {IZF }}=M g$ in der intrazellulären Flüssigkeit ( $\left.\mathrm{mMol} / \mathrm{kg}\right)$

$[\mathrm{Mg}]_{\text {ges. }}=$ Gesamtgehalt an $\mathrm{Mg}$ bezogen auf $1 \mathrm{~kg} \mathrm{FG}$

$[\mathrm{Mg}]_{\text {EZF }}=$ extrazelluläres $\mathrm{Mg}$ in $1 \mathrm{~kg} \mathrm{FO}$

$\mathrm{EZF}=$ Größe der EZF in $l / \mathrm{kg} \mathrm{FG}$

\section{Feblerrecbnung}

Der mittlere absolute Fehler des Mittelwertes ( $f$ ) wurde berechnet nach:

$$
\begin{aligned}
& \mathrm{f}= \pm \sqrt{\frac{\sum\left(\overline{\mathrm{x}}-\mathrm{x}_{1}\right)^{2}}{n(n-1)}} \\
& \overline{\mathrm{x}}=\text { Mittelwert } \quad \mathrm{x}_{1}=\text { Einzelwert } \mathrm{n}=\text { Anzahl der Tiere }
\end{aligned}
$$

\section{Feblerfortpflanzung}

Ein Teil der Ergebnisse kann nicht direkt gemessen werden, sondern muß aus anderen Messungen, die einen bestimmten Fehler haben, errechnet werden. Die Fehler der Meßgrößen gehen in den Fehler (fe) der errechneten Größe ein.

$$
\begin{gathered}
f_{e}= \pm \sqrt{f_{1}^{2}+f_{2}^{2}+f_{3}^{2} \cdots} \\
f_{e}=\text { fortgeleiteter Fehler } \\
f_{1}, f_{2} \ldots=\text { Fehler der einzelnen Messungen }
\end{gathered}
$$

Bei Addition und Subtraktion muß für $f_{1}$ der absolute Fehler, bei Multiplikation und Division der relative Fehler eingesetzt werden.

Signifikanz

Die Signifikanz wurde nach folgender Formel abgeschätzt:

Vorbehandlung der einzelnen Versuchsgruppen

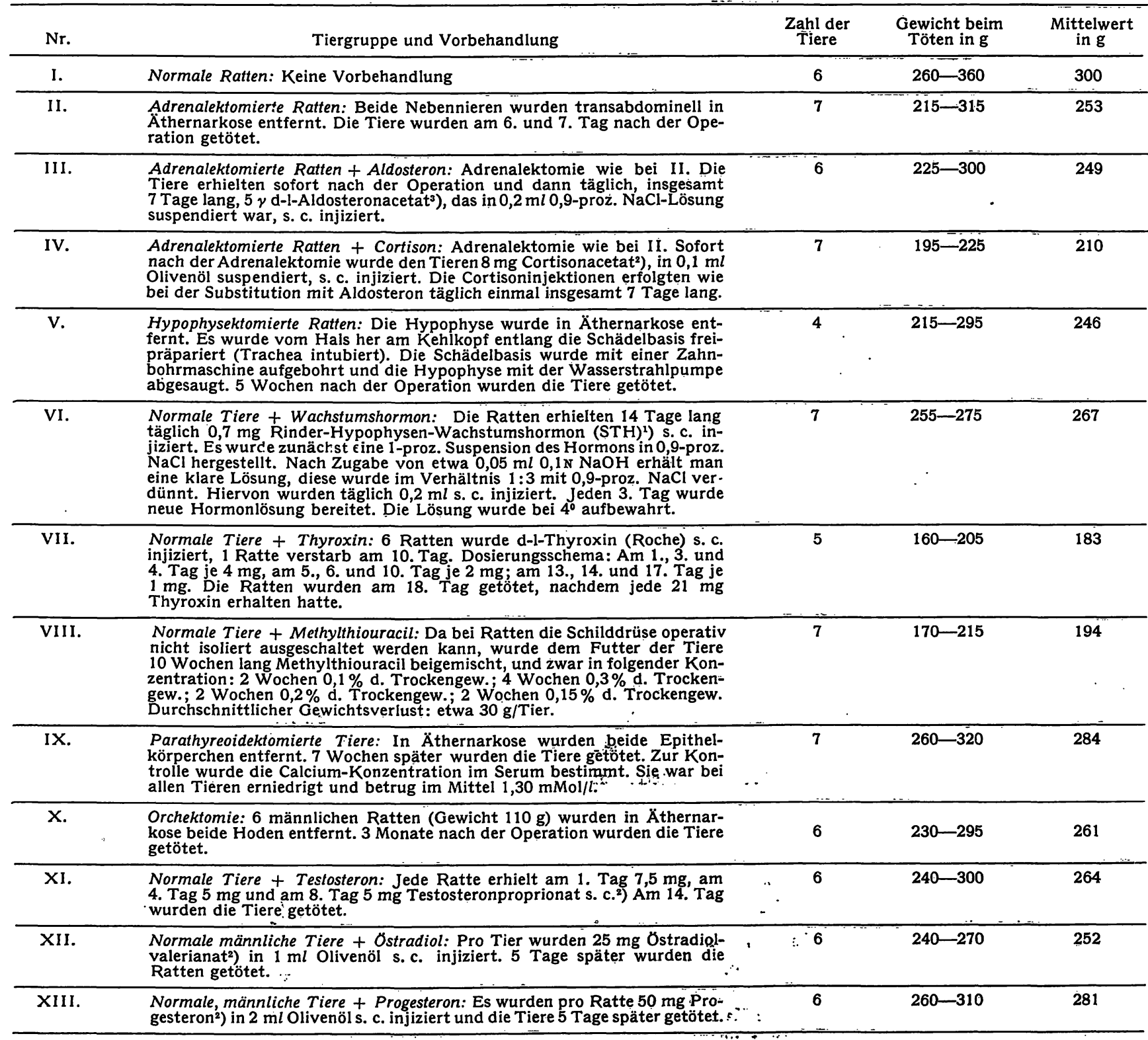

1) Wir danken Dr. E. WILHELMr, National Institute of Health, Endocrinol. Section, Bethesda, Mạd., für die großzügige Überlassung des gereinigten STH (NIH-GH-B

2) Präparate der $\mathrm{Fa}$. Schering, Berlin

?) Präparate der Fa. Schering, Ber

Für die freundliche Überlassung der Präparate sei beiden Firmen gedankt. 


$$
\mathrm{t}=\frac{\mathrm{m}_{1}-\mathrm{m}_{2}}{\sqrt{\mathrm{f}_{1}^{2}+\mathrm{f}_{2}^{2}}}
$$

$m_{1}, m_{2}=$ Mittelwerte zweier Versuchsserien

$m_{1}, m_{2}=$ Mittelwerte zweier Versuchsserien
$f_{1}, f_{2}=$ mittlerer, absoluter Fehler von $m_{1}$ bzw $m_{2}$

Die den Werten von $t$ entsprechende Signifikanz $P$ kann aus den Tabellen von FIsfer (8) abgelesen werden. Unter den gewählten Versuchsbedingungen (6-7 Tiere/Versuchsserie) soll eine Differenz zwischen zwei Versuchsserien signifikant sein, wenn $t>2$ $(P<0,05)$ ist.

\section{Ergebnisse}

\section{Hypophyse}

Entfernen der Hypophyse hat keinen signifikanten Einfluß auf die $\mathrm{Mg}$-Konzentration im Serum. Injiziert man dagegen normalen Ratten zusätzlich 14 Tage lang Rinderhypophysen-Wachstumshormon (STH), das bei Ratten keine Antikörper erzeugt (9), so sinkt die $\mathrm{Mg}$ Serumkonzentration auf $0,88 \mathrm{mMol}$ (Tab. 1). Das gleiche fanden HaNNa und Mitarbeiter am Menschen (10). Nach Injektion von $5 \mathrm{mg}$ bzw. $10 \mathrm{mg}$ STH sank die $\mathrm{Mg}$-Konzentration im Serum um etwa 0,2 mMol. Umgekehrt stieg die bei acromegalen Patienten erniedrigte $\mathrm{Mg}$-Konzentration nach Ausschaltung der Hypophyse wieder an.
Nach Hypophysektomie fanden wir in der Leber keine Änderung des intrazellulären Mg-Gehaltes, im Muskel verringerte er sich. Nach Gabe von STH an normale Ratten nahm der $\mathrm{Mg}$-Bestand in der Leber ab und im Muskel zu (Tab. 2, 3).

Die Abnahme des $\mathrm{Mg}$-Gehaltes in der Muskulatur nach Hypophysektomie könnte durch das Fehlen des STH bedingt sein. Umgekehrt, wenn STH zusätzlich gegeben wird, steigt der Mg-Gehalt in der Muskulatur. Da STH zu einer Steigerung des aktiven Transportes von Aminosäuren (11) und Glukose (12) führt, könnte die durch STH bewirkte $\mathrm{Mg}$-Zunahme in der Muskulatur analog ebenfalls durch eine (noch zu beweisende) Steigerung des aktiven $\mathrm{Mg}$-Transportes zustande kommen. Die Abnahme des $\mathrm{Mg}-\mathrm{Ge}-$ haltes in der Leber nach Zufuhr von STH könnte eine Folge der Abnahme der Mg-Konzentration im Serum sein.

Bei Bilanzversuchen (10) bewirkte STH eine vermehrte Resorption von $\mathrm{Mg}$ im Darm und eine erhöhte $\mathrm{Mg}$-Ausscheidung durch die Niere. Dieses Ergebnis wird verständlich, wenn man wiederum annimmt, daß STH den $\mathrm{Mg}$-Transport erhöht. Bei ungenügender $\mathrm{Mg}$-Zufuhr mit der Nahrung könnte STH deswegen zu einer negativen $\mathrm{Mg}$-Bilanz und vielleicht auch über diesen Weg zu einer Verminderung der Serum-Mg-Konzentration führen.

Tab. 1. Serumproteinkonzentration, Mg-Konzentration im Serum und Ultrafiltrat des Serums (Bestimmung s. Methode) sowie Menge der extrazellulären Flüssigkeit (EZF) und Wassergehalt in Lebern und Muskeln bei verschiedenen Tiergruppen

\begin{tabular}{|c|c|c|c|c|c|c|c|}
\hline Tiergruppe & $\begin{array}{c}\text { Serumprotein } \\
{[\%]}\end{array}$ & \multicolumn{2}{|c|}{$\begin{array}{l}\text { [Mg] in mMol/l } \\
\text { Serum Ultr. }\end{array}$} & \multicolumn{2}{|c|}{$\mathrm{EZF}$ in \% } & \multicolumn{2}{|c|}{$\begin{array}{l}\text { Wassergehalt in } \% \\
\text { Leber }\end{array}$} \\
\hline $\begin{array}{l}\text { Normale Tiere } \\
\text { Hypophysektomierte Tiere } \\
\text { Normale Tiere + STH } \\
\text { Adrenalektomierte Tiere } \\
\text { Adrenalekt. Tiere + Aldosteron } \\
\text { Adrenalekt. Tiere + Cortison } \\
\text { Normale Tiere + Methylthiourac. } \\
\text { Normale Tiere + Thyroxin } \\
\text { Parathyreoidektomierte Tiere } \\
\text { Kastrierte Tiere } \\
\text { Normale Tiere + Testosteron } \\
\text { Normale Tiere + Ostradiol } \\
\text { Normale Tiere + Progesteron }\end{array}$ & $\begin{array}{l}7 ; 77 \pm 0,47 \\
7,39 \pm 0,30 \\
6,52 \pm 0,19 \\
6,27 \pm 0,29 \\
7,05 \pm 0,23 \\
6,60 \pm 0,07 \\
7,54 \pm 0,43 \\
6,60 \pm 0,13 \\
6,84 \pm 0,33 \\
7,97 \pm 0,20 \\
7,93 \pm 0,30 \\
7,05 \pm 0,11 \\
5,90 \pm 0,08\end{array}$ & $\begin{array}{l}0,99 \pm 0,04 \\
1,00 \pm 0,01 \\
0,88 \pm 0,04 \\
1,17 \pm 0,03 \\
0,96 \pm 0,03 \\
1,23 \pm 0,03 \\
0,71 \pm 0,02 \\
1,25 \pm 0,02 \\
0,90 \pm 0,03 \\
1,18 \pm 0,03 \\
1,23 \pm 0,04 \\
1,00 \pm 0,02 \\
1,11 \pm 0,02\end{array}$ & $\begin{array}{l}0,67 \\
0,68 \\
0,61 \\
0,85 \\
0,68 \\
0,88 \\
0,47 \\
0,89 \\
0,62 \\
0,79 \\
0,81 \\
0,70 \\
0,80\end{array}$ & $\begin{array}{l}19,2 \pm 1,0 \\
18,4 \pm 1,6 \\
19,2 \pm 1,0 \\
15,9 \pm 0,8 \\
17,0 \pm 0,5 \\
17,0 \pm 0,6 \\
18,6 \pm 0,7 \\
25,4 \pm 1,2 \\
17,6 \pm 0,3 \\
17,7 \pm 0,6 \\
24,7 \pm 1,3 \\
17,2 \pm 0,2 \\
16,8 \pm 0,3\end{array}$ & $\begin{array}{r}9,4 \pm 0,6 \\
10,9 \pm 0,7 \\
10,8 \pm 0,2 \\
9,9 \pm 1,1 \\
11,9 \pm 0,4 \\
10,0 \pm 0,7 \\
16,2 \pm 0,5 \\
10,4 \pm 0,4 \\
10,3 \pm 1,2 \\
10,3 \pm 2,8 \\
14,9 \pm 0,5 \\
9,6 \pm 0,1 \\
8,1 \pm 0,2\end{array}$ & $\begin{array}{l}68,97 \pm 0,35 \\
68,80 \pm 0,50 \\
69,20 \pm 0,27 \\
72,00 \pm 0,16 \\
71,10 \pm 0,30 \\
68,06 \pm 0,29 \\
68,74 \pm 0,22 \\
69,15 \pm 0,19 \\
67,74 \pm 0,19 \\
68,26 \pm 0,28 \\
69,62 \pm 0,39 \\
68,65 \pm 0,20 \\
68,20 \pm 0,16\end{array}$ & $\begin{array}{l}74,10 \pm 0,29 \\
73,77 \pm 0,05 \\
74,37 \pm 0,10 \\
74,44 \pm 0,24 \\
74,20 \pm 0,20 \\
73,33 \pm 0,17 \\
74,58 \pm 0,25 \\
72,41 \pm 0,10 \\
74,21 \pm 0,15 \\
74,20 \pm 0,38 \\
74,96 \pm 0,25 \\
74,50 \pm 0,03 \\
74,70 \pm 0,11\end{array}$ \\
\hline
\end{tabular}

Tab. 2. MG-Gehalt in den Lebern der einzelnen Versuchsgruppen bezogen auf kg Trockengewicht (T. G.) und kg Feuchtgewicht (F. G.) sowie extrazellulärer MG-Bestand in mMol/kg FG (EZ) und intrazellulärer Mg-Gehalt in mMol/kg Zellen (IZ) (Berechnung s. Methode)

\begin{tabular}{|c|c|c|c|c|}
\hline Tiergruppe & T. G. & $\begin{array}{c}\text { Magnesi } \\
\text { F. G. }\end{array}$ & $\underset{\mathrm{EZ}}{\mathrm{mMol} / \mathrm{kg}}$ & IZ \\
\hline $\begin{array}{l}\text { Leber } \\
\text { Normale Tiere } \\
\text { Hypophysektomierte Tiere } \\
\text { Normale Tiere + STH } \\
\text { Adrenalektomierte Tiere } \\
\text { Adrenalekt. Tiere + Aldosteron } \\
\text { Adrenalekt. Tiere + Cortison } \\
\text { Normale Tiere + Methylthiourac. } \\
\text { Normale Tiere + Thyroxin } \\
\text { Parathyreoidektomierte Tiere } \\
\text { Orchektomierte Tiere } \\
\text { Normale Tiere + Testosteron } \\
\text { Normale Tiere + Ostradiol } \\
\text { Normale Tiere + Progesteron }\end{array}$ & $\begin{array}{l}30,61 \pm 0,52 \\
30,00 \pm 0,52 \\
27,94 \pm 0,51 \\
37,27 \pm 0,68 \\
33,30 \pm 0,66 \\
25,81 \pm 0,37 \\
27,23 \pm 0,29 \\
35,46 \pm 0,39 \\
27,41 \pm 0,34 \\
29,12 \pm 0,16 \\
30,57 \pm 0,26 \\
28,02 \pm 0,27 \\
28,30 \pm 0,25\end{array}$ & $\begin{array}{r}9,50 \pm 0,19 \\
9,36 \pm 0,24 \\
8,61 \pm 0,17 \\
10,45 \pm 0,20 \\
9,62 \pm 0,22 \\
8,25 \pm 0,14 \\
8,51 \pm 0,11 \\
10,94 \pm 0,14 \\
8,84 \pm 0,12 \\
9,25 \pm 0,10 \\
9,28 \pm \pm 0,12 \\
8,79 \pm 0,10 \\
9,00 \pm 0,09\end{array}$ & $\begin{array}{l}0,144 \pm 0,02 \\
0,153 \pm 0,02 \\
0,130 \pm 0,02 \\
0,147 \pm 0,02 \\
0,126 \pm 0,02 \\
0,164 \pm 0,03 \\
0,098 \pm 0,01 \\
0,249 \pm 0,03 \\
0,121 \pm 0,02 \\
0,157 \pm 0,02 \\
0,226 \pm 0,03 \\
0,134 \pm 0,02 \\
0,148 \pm 0,02\end{array}$ & $\begin{array}{r}11,58 \pm 0,15 \\
11,24 \pm 0,22 \\
10,50 \pm 0,20 \\
12,25 \pm 0,27 \\
11,44 \pm 0,27 \\
9,74 \pm 0,19 \\
10,34 \pm 0,16 \\
14,34 \pm 0,29 \\
10,57 \pm 0,15 \\
11,05 \pm 0,14 \\
12,02 \pm 0,17 \\
10,45 \pm 0,12 \\
10,65 \pm 0,12\end{array}$ \\
\hline
\end{tabular}

Tab. 3. MG-Gehalt in der Musskulatur. der einzelnen Versuchsgruppen (s. u. Tab. 2)

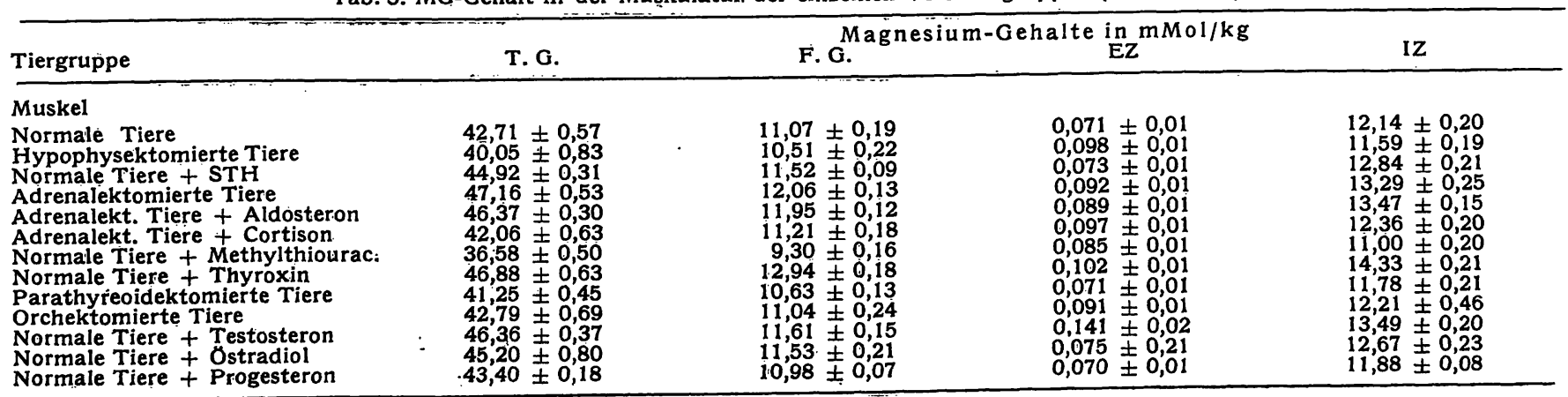




\section{Nebennierenrinde}

Nach Entfernung beider Nebennieren stieg bei Ratten die Mg-Konzentration im Serum von $0,99 \mathrm{mMol}$ auf $1,17 \mathrm{mMol}$ an (Tab. 1). Bei nebennierenlosen Hunden fanden SwiNGLE und Mitarbeiter (13) eine noch stärkere Zunahme der Mg-Konzentration von etwa $1 \mathrm{mMol}$ auf 1,5-2,0 mMol. Eine Zunahme der Mg-Konzentration im Serum nach Adrenalektomie beobachteten außerdem Conway und Mitarbeiter (14) an Ratten, Harrop und Mitarbeiter (15) bei Hunden und ZWEMER und Mitarbeiter (16) bei Katzen. Injiziert man adrenalektomierten Ratten sofort nach der Operation täglich $5 \mu \mathrm{g}$ Aldosteron, so läßt sich das Ansteigen der Mg-Konzentration im Serum verhindern (Tab. 1). Ähnlich konnte SwINGLE (13) die bei nebenniereninsuffizienten Hunden erhöhte Mg-Konzentration im Serum durch Injektion von Aldosteron wieder senken. Analog war bei einem Patienten mit erhöhter Produktion von Mineralocorticoiden die Mg-Konzentration im Serum erniedrigt (17). Gibt man Ratten sofort nach der Adrenalektomie täglich $8 \mathrm{mg}$ Cortison, so kommt es wie nach alleiniger Adrenalektomie zu einer Zunahme der Mg-Konzentration im Serum (Tab. 1). Mg verhält sich also im Serum qualitativ wie $\mathrm{K}$. Es bestehen jedoch quantitative Unterschiede. Durch Aldosteron sank die bei nebennierenlosen Hunden ebenfalls erhöhte K-Konzentration schneller als die $\mathrm{Mg}-$ Konzentration (13).

Im. Gewebe fanden wir nach Adrenalektomie in Leber und Muskulatur eine Zunahme des Mg-Gehaltes. Das gleiche Ergebnis erhielten auch HINGERTY (18) und HANNA und Mitarbeiter (10) am Muskel.

Die Zunahme des Mg-Gehaltes im Serum und Gewebe nach Adrenalektomie könnte durch eine verminderte Ausscheidung des $\mathrm{Mg}$ zustande kommen (19). Die erhöhte $\mathrm{Mg}$-Konzentration im Serum kann dann zu einer erhöhten $\mathrm{Mg}$-Aufnahme in die Zellen führen.

Nach Substitution mit Aldosteron fanden wir den $\mathrm{Mg}$ Gehalt in der Leber niedriger als bei adrenalektomierten Tieren, aber noch höher als bei normalen Ratten, im Muskel war gegenüber adrenalektomierten Ratten kein Unterschied festzustellen. Aldosteron kann demnach die Folgen der Adrenalektomie hinsichtlich des $\mathrm{Mg}-\mathrm{Ge}-$ haltes im Serum vollständig, im Gewebe aber nur teilweise normalisieren.

Die Abnahme des $\mathrm{Mg}$ aus der Leber adrenalektomierter Tiere unter Aldosteron läßt sich durch eine Verstärkung der Mg-Ausscheidung durch Aldosteron erklären (19). Neben dieser renalen Wirkung scheint Aldosteron noch die $\mathrm{Mg}$-Aufnahme durch die Zellmembran zu hemmen (20), was ebenfalls zu einer Abnahme des zellulären Mg-Gehaltes führen kann.

Nach Substitution mit Cortison dagegen war der MgGehalt in der Leber erheblich geringer als bei Normaltieren. Im Muskel konnten wir keine signifikante Abnahme feststellen. Die Ursache, weshalb die Änderungen des $\mathrm{Mg}$-Stoffwechsels an der Muskulatur nicht zum Ausdruck kommen, könnte darauf beruhen, daß im Muskel nur ein geringer Teil des $\mathrm{Mg}$ austauschbar ist, während z. B. in der Leber der Mg-Bestand vollständig und schnell ausgetauscht wird (21), der Umsatz in der Leber also wesentlich schneller erfolgt.
Der Mg-Gehalt in der Leber nimmt unter Cortison ab, obwohl die extrazelluläre $\mathrm{Mg}$-Konzentration erhöht ist. Diese Abnahme des $\mathrm{Mg}$-Gehaltes beruht wahrscheinlich auf einer Abnahme des $\mathrm{Mg}$-Komplexbildners ATP, bedingt durch Entkoppelung der oxydativen Phosphorylierung, welche bei hohen Cortisondosen (täglich $5 \mathrm{mg} /$ Ratte, 7 Tage lang) erfolgt (22).

Hingerty (18) interpretierte die Nebenniereninsuffizienz an Hand der dabei auftretenden Änderungen der $\mathrm{Mg}$-Verteilung. Danach soll die Erhöhung der extrazellulären $\mathbf{M g}$-Konzentration zu einer Erhöhung der intrazellulären $\mathrm{Mg}$-Ionenkonzentration führen. Die erhöhte intrazelluläre $\mathrm{Mg}$-Ionenkonzentration soll die Aktivität $\mathrm{Mg}$-abhängiger Enzyme derart beeinflussen, daß die Symptome der Nebenniereninsuffizienz resultieren, ư. a. eine Erhöhung der ATP-Konzentration, obwohl durch Adrenalektomie der P/OQuotient nicht verändert wird (23). Diese Vorstellung ist wahrscheinlich zu einfach. Es ist unwahrscheinlich, daß durch die geringe Erhöhung der extrazellulären $\mathrm{Mg}$-Konzentration eine ausreichende Änderung des intrazellulären pMg, der die Aktivität Mg-abhängiger Enzyme (bei Sättigung mit den anderen Komponenten) bestimmt, hervorgerufen wird (4). Außerdem müßten dann andere Zustände mit gleicher, erhöhter $\mathrm{Mg}$-Konzentration die Erscheinungen der Nebenniereninsuffizienz erzeugen.

\section{Schilddrüse}

Werden Ratten hypothyreoid gemacht, indem man ihnen 10 Wochen lang Methylthiouracil-haltiges Futter gibt, dann sinkt die Mg-Konzentration im Serum von $0,99 \mathrm{mMol}$ auf $0,70 \mathrm{mMol}$ ab (Tab. 1). Injiziert man Ratten $2 \frac{1}{2}$ Wochen lang Thyroxin (inssgesamt $21 \mathrm{mg}$ ), so steigt die $\mathrm{Mg}-$ Konzentration im Serum auf 1,25 mMol. Bei Patienten mit Úber- bzw. Unterfunktion der Schilddrüse waren keine Änderungen der Serum-Mg-Konzentration und des ultrafiltrierbaren $\mathrm{Mg}$ gegenüber gesunden Personen festzustellen $(24,25)$. Nach Bisser (26) ist bei Hyperthyreosen der Anteil des proteingebundenen $\mathrm{Mg}$ erhöht, bei Hypothÿreosen erniedrigt. AIKawa (27) stellte bei Kaninchen, die zweimal 0,3 mg Thyroxin/kg erhalten hatten, eine Abnahme der $\mathrm{Mg}$-Konzentration im Serum fest. Diese Diskrepanz ergibt sich wahrscheinlich aus den extremen Versuchsbedingungen, die man wählen muß, um bei Ratten eine Hyperthyreose zu erreichen.

Im Gewebe war bei hypothyreoiden Ratten der MgGehalt in Leber und Muskulatur abgesunken. Nach der Zufuhr von Thyroxin war er umgekehrt in Leber und Muskulatur angestiegen (Tab. 2,3). Hiermit in Übereinstimmung fand AIKAwA (27) bei Kaninchen nach Gaben von Propylthiouracil eine Abnahme der relativen Radioaktivität des $\mathrm{Mg}^{28}\left(\frac{\mathrm{cpm} / \mathrm{g} \text { Gewebe }}{\mathrm{cpm} / \mathrm{ml} \text { Plasma }}\right)$ in der Leber und nach Injektion von Thyroxin einen Anstieg der relativen Radioaktivität in Haut, Appendix, Leber und Herzmuskel. $\mathrm{Da}$ das $\mathrm{Mg}$ in diesen Organen vollständig austauschbar ist, ist die relative Radioaktivität ein $\mathrm{Maß}$ für den $\mathrm{Mg}$-Gehalt.

Úber die Ursachen dieses Verhaltens läßt sich nichts aussagen. Nach Arkawa (27) soll die Mg-Bilanz durch Propylthiouracil oder Thyroxin nicht signifikant verändert sein. $\mathrm{Da}$ bei vergleichbar hohen Thyroxindosen eine Entkoppelung der oxydativen Phosphorylierung in der Leber erfolgt (28), müßte die Zunahme des Mg-Gehalteś 
bei gleichzeitiger Abnahme des ATP-Gehaltes erfolgt sein.

\section{Nebenschilddrüse}

Nach Entfernung der Epithelkörperchen nimmt die Mg-Konzentration bei Ratten im Serum von 0,99 auf $0,90 \mathrm{mMol} \mathrm{ab}$ (Tab. 1). Bei denselben Tieren war die CaKonzentration, die ein Maß für die Aktivität des Parathormons ist, von 2,50 auf $1,30 \mathrm{mMol}$ abgesunken. Ein entsprechendes Verhalten konnte bei einem Patienten mit einem Adenom der Nebenschilddrüse beobachtet werden. Nach Entfernung des Tumors sank die stark erhöhte Ca-Konzentration auf den normalen Wert, die $\mathrm{Mg}-$ Konzentration nahm nur wenig ab (29). Umgekehrt bewirkt Injektion von Parathormon bei Hunden (100 $\mathrm{E} / 10-15 \mathrm{~kg}$ ) eine durchschnittliche Erhöhung der Serum-Mg-Konzentration um 0,25 mMol, die der Erhöhung der Ca-Konzentration um $15 \mathrm{Stdn}$. vorausgeht (30).

Die Abnahme der Mg-Konzentration im Serum nach Entfernen der Epithelkörperchen läßt sich mit einer erhöhten $\mathrm{Mg}$-Ausscheidung erklären, die bei Fehlen des Parathormons resultiert, denn in Bilanzversuchen an parathyreoidektomierten Ratten fanden MACINTYRE und Mitarbeiter (31), daß Parathormon bei intravenöser Infusion einer Elektrolytlösung eine Retention von $\mathrm{Mg}$ bewirkt, die mit dem Logarithmus der zugeführten Hormonmenge ansteigt. Im Gegensatz hierzu wurde allerdings bei Patienten mit einer Uberfunktion der Epithelkörperchen eine negative $\mathrm{Mg}-\mathrm{Bilanz}$ beobachtet, die nach Entfernung des Adenoms positiv war $(32,33)$. Im Gewebe nahm nach Parathyreoidektomie der $\mathrm{Mg}$ Gehalt nur in der Leber ab. Die Abnahme in der Muskulatur ist nicht signifikant (Tab. 2, 3). Die Abnahme des $\mathrm{Mg}-$ Gehaltes in der Leber kann sekundär durch die Abnahme der $\mathrm{Mg}$-Konzentration im Serum bedingt sein. $\mathrm{Da}$ sich diese an der Leber und nicht am Muskel auswirkt, läßt sich wieder damit erklären, daß das $\mathrm{Mg}$ in der Leber wesentlich schneller als im Muskel umgesetzt wird.

\section{Sexualhormone}

Nach Exstirpation beider Hoden stieg die Mg-Konzentration im Serum auf $1,18 \mathrm{mMol}$. Wurde normalen männlichen Ratten Testosteron injiziert, stieg die $\mathrm{Mg}$ Konzentration im Serum auf $1,23 \mathrm{mMol}$ und nach Injektion von Progesteron auf $1,11 \mathrm{mMol}$. Östradiol hatte keinen Einflu $ß$ auf die Serum-Mg=Konzentration (Tab. 1). Ähnliche Ergebnisse wurden an Patientinnen erzielt (34). Nach Kastration war die Mg-Konzentration im Serum erhöht. Zufuhr von Androgenen hatte den gleichen Effekt. Östrogene dagegen senkten die $\mathrm{Mg}$ Konzentration im Serum.

Im Gewebe fanden wir nach Exstirpation beider Hoden keine signifikanten Änderungen des Mg-Gehaltes. Nach Testosterongaben wàr der Mg-Gehalt im Muskel exhöht und in der Leber unverändert. Unter Östradiol nahm der $\mathrm{Mg}$-Gehalt der Muskulatur zu, während der Mg-Bestand in der Leber abnahm. Damit in Úbereinstimmung wurde nach Injektion vọn Östradiol eine Zunahme des $\mathrm{Mg}$-Gehaltes in der Uterusmuskulatur gefunden $(35,36)$. Progesteron schließlich hatte im Muskel keine Wirkung und führte in der Leber zu einer Abnahme des $\mathrm{Mg}$ Gehaltes.

\section{Diskussion}

Die Aufnahme von $\mathrm{Mg}$ in die Zelle war bei in vitro-Versuchen von der extrazellulären Konzentration von $\mathrm{Na}$, $\mathrm{K}, \mathrm{Ca}, \mathrm{PO}_{4}$ und Glukose abhängig (4). Hormonell bedingte Konzentrationsänderungen dieser Substanzen könnten also auch sekundär die Aufnahme und Verteilung des $\mathrm{Mg}$ beeinflussen. Die in vitro erforderlichen Konzentrationsänderungen zur meßbaren Änderung der $\mathrm{Mg}$-Aufnahme sind allerdings so groß, daß sie bei in vivo-Versuchen nicht erreicht werden.

Die durch Hormone bewirkten Änderungen des $\mathrm{Mg}$ Gehaltes sind relativ gering. Sie betragen maximal etwa $\pm 20 \%$ und haben etwa die gleiche Größenordnung wie die durch Hormone hervorgerufenen Änderungen des zellulären K-Gehaltes. Es besteht jedoch kein streng paralleles Verhalten $z$ wischen $\mathrm{K}$ und $\mathrm{Mg}$, obgleich beide „zelluläre Ionen“" sind. So verhalten sich z. B. K und $\mathrm{Mg}$ bei verschiedenen Zuständen der Nebennierentinde oder nach Thyroxingaben im Serum identisch, nicht aber im Gewebe. Umgekehrt änderten sich $\mathrm{K}$ und $\mathrm{Mg}$ nach $\mathrm{Zu}$ fuhr von Sexualhormonen oder STH im Gewebe gleichsinnig, nicht aber im Serum. Dieses Verhalten ist verständlich, wenn man bedenkt, daß Hormone sehr komplexe, im einzelnen noch nicht überschaubare Wirkungen an der Zelle ausüben und $\mathrm{K}$ und $\mathrm{Mg}$ sich hinsichtlich ihrer Fähigkeit, Chelate zu bilden, unterscheiden. Dieses nicht gleichsinnige Verhalten $z$ wischen $\mathrm{Mg}$ und anderen Kationen spricht aber auch für eine unabhängige hormonelle Steuerung des $\mathrm{Mg}$ und gegen die Vermutung, $\mathrm{da} ß$ Änderungen der Mg-Verteilung sekundär die Folge einer veränderten $\mathrm{Na}$ - oder $\mathrm{K}$-Verteilung sind.

Der extrazelluläre $\mathrm{Mg}$-Bestand, der nur etwa $1 \%$ des Gesamt-Mg-Bestandes beträgt (Tab. 2, 3), ändert sich mit der Größe der EZF, der Mg-Serum-Konzentration, der Serumprotein-Konzentration sowie mit dem Verhältnis von intravasalem : extravasalem Anteil der EZF (s. Methodik). Das Verhalten der EZF wurde an anderer Stelle behandelt $(1,2,3)$. Auf ihre Besprechung wird daher verzichtet.

Angaben über den Zustand des $\mathrm{Mg}$ in der Zelle nach einer Änderung des intrazellulären Mg-Gehaltes sind nicht möglich. $\mathrm{Mg}$ ist in der Zelle größtenteils komplex gebunden und nur zu einem geringen Teil ionisiert (4). Beide Komponenten können sich wahrscheinlich unäbhängig voneinander und vielleicht auch in entgegengesetzter Richtung ändern. Wenn z. B. der Gehalt an ATP oder anderen Mg-Komplexbildnern in der Zelle abnimmt, sinkt zwangsläufig auch die Konzentration des komplex gebundenen $\mathrm{Mg}$. $\mathrm{Da}$ sich das ionisierte $\mathrm{Mg}$ in der Zelle in einem Puffer-Gleichgewicht befindet (4), wird beim Freisetzen von Mg-Ionen z. B. aus MgATP ein Teil des $\mathrm{Mg}$ von Komplexbildnern mit einer geringeren $\mathrm{Mg}$-Komplexbildungskonstanten als ATP gebunden. Dennoch kann die Mg-Ionenkonzentration zunehmen, wenn nämlich bei konstant bleibendem $\mathrm{Mg}$ Influx die freigesetzten $\mathrm{Mg}$-Ionen nicht aus der Zelle permeieren.

Aussagen über das Verhalten des aktiven Transportes unter verschiedenen hormonellen Bedingungen, die bei 
der Na-K-Verteilung möglich waren $(1,2,3)$, sind beim Mg nicht möglich. Dazu müßte die Konzentration des ionisierten $\mathrm{Mg}$ unter den jeweiligen Bedingungen in der Zelle bekannt sein.

$\mathrm{Da} \mathrm{Mg}$ zahlreiche Enzyme in der Zelle aktiviert, ist zu diskutieren, ob die beobachteten Änderungen des $\mathrm{Mg}$ Gehaltes ursächlich an der Wirkung der verschiedenen Hormone beteiligt sind. Die Änderung des intrazellulären Gesamt-Mg-Bestandes sind zwar gering. Wie diese
Änderungen des Mg-Bestandes die einzelnen Zellfraktionen (wie Mitochondrien, Ribosomen, Cytoplasma usw.) betreffen, ist unbekannt. Wie sich unter hormonellen Einflüssen die Konzentrationen an $\mathrm{Mg}$-Komplexbildnern in diesen Zellorganellen verhalten, ist ebenfalls unsicher. Deshalb lassen sich noch keine Aussagen über die $\mathrm{Mg}$-Ionenkonzentrationen an den Wirkungsorten des $\mathrm{Mg}$ in der Zelle und über eine Beteiligung des $\mathrm{Mg}$ am Zustandekommen von Hormonwirkungen machen.

\title{
Literatur
}

1. Dulce, H.-J., Th. GüNther und E. Schütte, Clin. Chim. A. 3, 423 (1958). - 2. Dulce, H.-J. und Th. GüNther, Arch. Exp. Path. Pharm. 238, 368 (1960). - 3. GüNther, Th., H.-J. Dulce und E. Schürte, Arch. Exp. Path. Pharm. 239, 283 (1960). - 4. GüNThER, Th., Habilitationsschrift, Berlin (1965). - 5. WeICHSELbaum, T. E., Amer. J. Chem. Path. 10, 49 (1956). - 6. Orange, M. und H. C. RheIN, J. biol. Chem. 189, 379 (1951). - 7. Willis, W. J. und F. W. Sunderaran, J. biol. Chem. 197, 343 (1952). 8. Fisher, R. A., Statistische Methoden für die Wissenschaft, Oliver and Boyd (1956). - 9. Lr, C. H., H. PAPkofF und C. W. Jordan, Proc. Soc. exp. Biol. Med. 100, 44 (1959). - 10. Hanna, S., L. McINTyre, M. T. HARrison und R. Fraser, Btit.Med. J.II, 12 (1961). - 11. NoAll, M. W., T. R. Riggs, L. M. WALKeR und H. N. Christensen, Science 126, 1002 (1957). - 12. Henderson, M. J., H. E. Morgan und C. R. Park, J. biol. Chem. 236, 2157 (1961). - 13. Da Vanzo, J. P., H. C. CRossfield und W. W. Swingle, Endocrin. 63, 825 (1958). - 14. Conway, E. J. und D. Hingerty, Biochem. J. 40, 561 (1946). - 15. Harrop, G. A., L. J. Soffer, R. ElLSWORTh und J. H. Trescher, J. exp. Med. 58, 17 (1933). - 16. ZwEMER, R. L. und R. C. SulLIVAN, Endocrin. 18, 97 (1934). - 17. MAder, J. und L. T. Iseri, Amer. J. Med. 19,
976 (1955). - 18. HrNGerTy, D., Biochem. J. 66, 429 (1957). 19. HanNa, S. und I. McIntyre, Lancet. II, 348 (1960). - 20. Ross, D. B. und A. D. Care, Biochem. J. 82, 21 (1962). - 21. Arkawa, J. K., E. L. Rhoades, D. R. Harms und J. Z. Reardon, Amer. J. Physiol. 197, 99 (1959). - 22. Kerppola, W., Endocrin. 67, 252 (1960). - 23. Strrckland, E. H., Arch. Biochem. Biophys. 100, 110 (1963). - 24. Cope, L. C. und N. WolfF, Biochem. J. 36, 413 (1942). - 25. KleEMAN, C. R., F. H. Epstein, D. KAY und E. Taborskx, J. Clin. Endocr. Metabol. 18, 1111 (1958). 26. Bisser, G. W., Amer. J. Med. Sci. 210, 195 (1945) zit. n. Simon, K. H., „Magnesium“ Stuttgart (1964) S. 29. - 27. Arkawa, J. K., Proc. Soc. exp. Biol. Med. 104, 594 (1960). — 28. Martius, C. und B. Hess, Biochem. Z. 326, 191 (1955): - 29. BarNes, B. A., S. M. Krane und O. Cope, J. Clin. Endocr. Metabol. 17, 1407 (1957). - 30. Greenberg, D. M., J. biol. Chem. 98, 765 (1932). 31. MCINTXRe, I., Nature 198, 1058 (1963). - 32. BuLger, H. A. und Mitarbeiter, J. Clin. Invest. 12, 1135 (1932). - 33. BARNES, B. A. und Mitarbeiter, J. Clin. Endocr. Metabol. 17, 1407 (1957). 34. von Nrda, S., zit. n. SrmọN, K. H., „Magnesium“ Stuttgart (1964) S. 20. - 35. WalaAs, O., Acta Physiol. Scand. 21, 27 (1950). - 36. Best, F. A. und V. R. Pickles, J. Endocrin. 32, 121 (1965).

Priv.-Doz. Dr. Th. Günther 1 Berlin 33, Arnimallee 22

\section{Zur Bestimmung des Kreatinins bei Ketonämie}

\author{
Von R. KattermanN \\ Aus der Medizinischen Universitätsklinik Göttingen (Direktor: Prof. Dr. W. Creutzfeldt)
}

(Eingegangen am 2. Juni 1966)

Da die Ketonkörper Aceton und besonders Acetacetat eine positive JAFFE-Reaktion geben, kann bei Ketonämie ein erhöhter Serumkteatiningehalt vorgetäuscht werden. Die Absorptionsspektren der mit Aceton, Acetacetat und Kreatinin gebildeten Farbstoffe sind praktisch identisch mit einem Maximum bei 490-500 $\mathrm{m} \mu$. Dagegen verhalten sich die molaren Extinktionskoeffizienten bei $546 \mathrm{~m} \mu$ in der Farbreaktion nach POPPER wie $1: 10: 150$, nach BoNSNEs wie $1: 20: 1000$. Kurzes Erhitzen eines Acetacetat-haltigen Serumüberstandes beseitigte den Ketonkörper-Störeffekt vollständig; damit ist es möglich, bei Patienten mit Ketoacidose zuverlässige Kreatininwerte zu errhalten.

Ketone bodies, especially acetoacetate, give a positive JAFFE reaction; in ketonaemia they may cause the determination of false "creatinine" values in the blood. The absorption spectra of the colours produced with acetone, acetoacetate and creatinine are practically identical, with maxima at $490-500 \mathrm{~m} \mu$. The molar extinction coefficients of the colour at $546 \mathrm{~m} \mu$ however, are $1: 10: 150$ according to Popper, and $1: 20: 1000$ according to BonsNes. The interference by ketone bodies in acetoacetate-containing serum supernatant is completely removed by brief heating; thus reliable creatinine values may be obtained for patients with ketoacidosis.

In der klinischen Routinediagnostik werden nicht selten Kreatininbestimmungen im Serum von Patienten veranlaßt, bei denen eine Erhöhung der Ketonkörper im Blut (z. B. Praecoma oder Coma diabeticum, Schwangerschaftsketonämie, ketonämisches Erbrechen bei Kindern) vorliegt. $\mathrm{Da}$ Acetacetat und Aceton mit alkalischem Pikrat eine Rotfärbung ergeben, resultieren in solchen
Fällẹn erhöhte „Kreatinin“-Werte, die evtl. Anlaß zu falschen differentialdiagnostischen Überlegungen sein können. $\mathrm{Da}$ in der Literatur keine näheren Angaben über diesen störenden Einfluß der Ketonkörper auf die Bestimmung des Kreatinins im Serum bzw. Urin vorlagen, andererseits in den letzten Jahren spezifische, enzymatische Bestimmungsmethoden ausgearbeitet wor- 